\title{
Energy levels of defects created in silicon supersaturated with transition
}

\section{metals}

\author{
H. GARCÍA ${ }^{1}$, H. CASTÁN ${ }^{1}$, S. DUEÑAS ${ }^{1}$, E. GARCÍA-HEMME ${ }^{2}$, R. GARCÍA- \\ HERNANSAZ ${ }^{2}$, D. MONTERO², and G. GONZÁLEZ-DÍAZ²
}

1.-Dpto. Electricidad y Electrónica. E.T.S.I. Telecomunicación. Universidad de Valladolid. Paseo de Belén 15. 47011 Valladolid (Spain).

2. — Dpto. Física Aplicada III (Electricidad y Electrónica). Facultad de Ciencias Físicas. Universidad Complutense de Madrid. Av. Complutense s/n. 28040 Madrid (Spain).

\footnotetext{
Abstract

Intermediate band in semiconductors have attracted much attention for their use in silicon-based solar cells and infrared detectors. In this work, $\mathrm{n}$-Si substrates were implanted with very high doses $\left(10^{13}\right.$ and $10^{14} \mathrm{~cm}^{-2}$ ) of vanadium, which gives rise to a supersaturated layer inside the semiconductor. However, the Mott limit was not overtaken. The energy levels created in the supersaturated silicon were studied in detail by means of thermal admittance spectroscopy. We have found a single deep center at an energy of $\mathrm{E}_{\mathrm{C}}-250 \mathrm{meV}$ or $\mathrm{E}_{\mathrm{C}}-200 \mathrm{meV}$ depending on the dose. This value agrees with one of the levels found for vanadium in silicon. The capture cross section values of the deep levels were also calculated, and we found a relationship between the capture cross section and the energy position of the deep levels which follows the Meyer-Neldel rule. This process usually appears in processes involving multiple excitations. The Meyer-Neldel energy values agrees with the ones previously obtained for silicon supersaturated with titanium and for silicon contaminated with iron.
} 


\section{INTRODUCTION}

The formation of an intermediate band (IB) in the midgap of a semiconductor has been has been widely studied in the last decade in order to induce infrared absorption in silicon substrates. A. Luque et al. ${ }^{1}$ proposed an increase in the theoretical efficiency limit of silicon solar cells established by Shockley and Queisser in $40.7 \%,{ }^{2}$ to values up to $63.1 \%$ in single junction solar cells based on semiconductors with an IB. The structure of an intermediate band solar cell enables an increase of the photo-generated current, as this approach allows electrons to be pumped from the valence band (VB) into the conduction band (CB) via the absorption of two photons with lower energies than the semiconductor band gap, without the output voltage of the cell being limited by this fact. 3

Another purpose of semiconductors with an intermediate band is the infrared detector area. ${ }^{4,5}$ Infrared detectors at room temperature is of interest in telecommunications and security. A room-temperature Si-based infrared detector is of great interest: silicon based detectors are low cost and CMOS compatibles. However, their band gap $(1.12 \mathrm{eV})$ limits the infrared response to wavelengths shorter than $1100 \mathrm{~nm}$. IB semiconductors are able to capture photons with energies below their bandgap due to the reduced gap from BV to IB or from IB to CB.

Intermediate bands in semiconductors can be obtained in several ways, for instance quantum dots in the semiconductor, ${ }^{6}$ or using highly mismatched alloys. ${ }^{7}$ Implanting semiconductor substrates with very high doses of transition metals $(\mathrm{V}, \mathrm{Ti}, \mathrm{Cr}, \ldots)$, obtaining a supersaturated semiconductor, is also a well-known method in order to form the IB, ${ }^{8}$ and is the way the silicon substrates were processed in this work.

The main goal of this work is studying the energy levels detected in silicon substrates when implanted with very high doses of vanadium $(\mathrm{V})$, a transition metal. The implanted metals create deep levels in the substrates that have been studied using the Thermal Admittance Spectroscopy technique (TAS). Using this technique, we are able to know both the energy position and the capture cross sections of the defects. The Mott limit $\left(5.9 \times 10^{19} \mathrm{~cm}^{-3}\right)$ is the theoretical doping concentration at which the IB is formed. ${ }^{9}$ Although we want to obtain knowledge of discrete levels inside the band gap of the silicon, in a previous work we observed that when the Mott limit is reached, the implanted metal does not act as non-radiative recombination defect. ${ }^{10}$ So we have studied the energy levels when very high metal concentrations are present in the silicon, but not high enough to overtake the Mott limit, and thereby, the levels of the traps can be obtained. 


\section{EXPERIMENTAL SET-UP}

Substrates used were $300 \mu \mathrm{m}$ thick $\operatorname{Si}(111) \mathrm{n}$-type $\left(\mu=1450 \mathrm{~cm}^{2} \mathrm{~V}^{-1} \mathrm{~s}^{-1} ; \rho=200 \Omega \mathrm{cm}\right)$. The samples were implanted in an ion beam service (IBS) refurbished VARIAN CF3000 Ion Implanter at $32 \mathrm{keV}$ with $\mathrm{V}^{51}$ doses of $10^{13}$, and $10^{14} \mathrm{~cm}^{-2}$. In order to get ohmic contacts on the bottom, the back side of the samples was implanted with phosphorous $\left(10^{15} \mathrm{~cm}^{2}\right.$ dose) at energy of $80 \mathrm{keV}$ before the $\mathrm{V}^{51}$ implantation. A rapid thermal annealing was carried out at a temperature of $900{ }^{\circ} \mathrm{C}$ for 20 seconds to activate the phosphorous. After the fabrication of the $\mathrm{n}^{+}$ layer on the bottom side, the top and bottom electrodes were deposited by evaporation of $100 \mathrm{~nm}$ titanium followed by evaporation of $200 \mathrm{~nm}$ aluminum. The implanted samples were annealed using the pulsed laser melting (PLM) method. ${ }^{11}$ The PLM annealing process was performed by IPG Photonics (New Hampshire, USA) with a 20 ns long pulse of a $\mathrm{KrF}$ excimer laser $(248 \mathrm{~nm})$ at energy density of $1 \mathrm{~J} / \mathrm{cm}^{2}$.

Supersaturation cannot be performed with equilibrium techniques, so non-equilibrium techniques are needed, as PLM. Using PLM technique, the silicon surface can be melted and recrystallized in very short times $\left(10^{-8} \mathrm{~s}-\right.$ $\left.10^{-6} \mathrm{~s}\right)$, and this allows the metal concentration to exceed the solubility limit for the element. ${ }^{12,13}$

Samples were studied by means of thermal Admittance Spectroscopy (TAS) technique, ${ }^{14}$ which yields thermal emission rates of deep levels from the variations of the capacitance and the conductance values of a Schottky or a p-n junction, as a function of the temperature and the frequency. Each deep level existing in the semiconductor band gap contributes with a peak in the conductance signal, and an inflection point in the capacitance signal.

The activation energy and the capture cross section of the deep level can be obtained from the Arrhenius plot of experimental data, using the equation ${ }^{15}$

$$
e^{t}(T)=\left(\sigma_{T} v_{t h} N_{C}\right) \cdot \exp \left(\frac{-E_{T}}{K_{T}}\right)
$$

$v_{t h}$ is the carrier thermal velocity which is proportional to $T^{1 / 2}, \sigma_{T}$ is the capture cross section and $N_{C}$ is the conduction band state density which is proportional to $T^{3 / 2}$.

An EG\&G 5210 lock-in amplifier together with a Femto DLPCA-200 current preamplifier were used to measure the conductance and the capacitance. The DC bias was applied using a Keithley 217 electrometer and an HP 33120A signal generator applied the small ac-signal needed to measure the impedance. Samples were cooled 
in darkness from room temperature to $77 \mathrm{~K}$ in an Oxford DM1710 cryostat. An Oxford ITC 502 was used to monitor and control the cryostat temperature.

\section{EXPERIMENTAL RESULTS}

Figure 1 shows the depth profiles of $\mathrm{V}$ atoms in the Si lattice, for as-implanted and PLM annealed samples. It has been measured by time-of-flight secondary ion mass spectrometry (ToF-SIMS). The Mott limit is clearly reached for doses of $10^{15}$ and $10^{16} \mathrm{~cm}^{-2}$. In the case of the dose of $10^{14} \mathrm{~cm}^{-2}$ the limit is reached, but only in a region very close to the surface. When the samples were annealed, there is a redistribution of the metal atoms: it is clear that the $\mathrm{V}$ atoms move towards the surface, as we can see a maximum in the concentration. The same redistribution behavior was observed when implanting titanium (Ti) in silicon substrates instead of V. ${ }^{16}$ An explanation was given by $\mathrm{C}$. W. White et al.: the impurities diffuse in liquid silicon and are incorporated into the solid silicon as the melt front moves towards the surface. ${ }^{17}$

In a previous work ${ }^{10}$ we observed that there were neither conductance peaks nor capacitance inflection points for $\mathrm{Si}$ doped with titanium above the Mott limit and for samples without implantation. It is an experimental evidence which agrees the IB theory, which claims that when the metal concentration exceeds the Mott limit and the IB has been formed, recombination centers due to the metal impurities are suppressed. Hence, we have only applied the TAS technique to samples implanted with $10^{13}$ and $10^{14} \mathrm{~cm}^{-2}$ doses in order to obtain the activation energies of the traps introduced by the vanadium implantation. As an example, Fig. 2 shows the TAS measurements for the sample implanted with a dose of $10^{13} \mathrm{~cm}^{-2}$ when no bias was applied. The small signal frequency varied from $77 \mathrm{~Hz}$ to $77 \mathrm{kHz}$. Figure 2a shows the peak measured in the conductance signal, whereas Fig. 2 b shows the inflection point in the capacitance signal. Using an Arrhenius plot, we can obtain the trap energy position inside the silicon band gap, as was explained in the Experimental set-up section. Figure 2c shows the Arrhenius plot. In the case of the sample implanted with a dose of $10^{13} \mathrm{~cm}^{-2}$, an energy position of about $260 \mathrm{meV}$ below the silicon conduction band was obtained. T. Sadoh et. al. measured the energy position of vanadium deep levels in silicon using the deep level transient spectroscopy (DLTS) technique. ${ }^{18}$ Both n-type and p-type silicon substrates were used in order to investigate trap levels in the upper and lower half of the silicon band gap, and they found three different levels: one acceptor level at $\mathrm{E}_{\mathrm{C}}-0.2 \mathrm{eV}$, and two donor levels at $\mathrm{E}_{\mathrm{C}}-0.45 \mathrm{eV}$ and at $\mathrm{E}_{\mathrm{V}}+0.34$ 
$\mathrm{eV}$. We are probably observing the acceptor level with an energy of $\mathrm{E}_{\mathrm{C}^{-}}-0.2 \mathrm{eV}$. We are not able to detect levels in the lower half of the band gap, as only n-type silicon substrates were available.

We have measured the energy position of the implanted vanadium for several reverse biases, ranging from 0 $\mathrm{V}$ to $-8 \mathrm{~V}$, and the obtained results are shown in Fig. 3. The energies remain fairly constant for all the bias applied. However, in a previous work, ${ }^{19}$ where titanium was implanted to the silicon substrates, we observed the energy values changed when varying the bias polarization. A model was then proposed: for high implantation doses (as the ones used in this work), the IB has not been formed yet, but the traps are so close that the interaction between them induces the energy levels splitting and a quasi-continuum energy band appears in a region near the surface. As reverse bias voltage increases, the pseudo-Fermi level crosses this quasi-continuum levels at different energy position, giving rise to different energy levels. On the other hand, the spectral photoconductivity of the samples studied in this work (implanted with V), but implanted with a dose of $10^{15} \mathrm{~cm}^{2}$, was measured (the Mott limit has been overtaken and the IB has been formed). ${ }^{20}$ The photoconductivity started to increase for photons with an energy near $0.4 \mathrm{eV}$. Perhaps, the energy level observed is not in the position where the intermediate band is formed, due to the constant value for the energy of the traps and because no spectral photoconductivity was detected at this low energy. The reason could be that deeper levels have lower emission rates, so the maximum in the conductance signal appears at higher temperatures. However, at higher temperatures the conductance signal becomes so large in these samples that the peak in the conductance signal is masked.

Using the TAS technique, the capture cross section of the deep levels was also measured. Using an Arrhenius plot (see Eq. 1), the slop shows us the energy position of the trap, and the cross at $x=0$ shows us the cross section. We have calculated the capture cross sections for different reverse bias voltages. Figure 4 shows the capture cross section $v s$. the energy position of the trap for the implanted with a dose of $10^{14} \mathrm{~cm}^{-2}$. We can observe a linear relationship. The same behavior was observed in the case of a dose of $10^{13} \mathrm{~cm}^{-2}$. This relation is called the MeyerNeldel (MN) rule, which claims that in physical parameters which follows an Arrhenius plot, there exists a linear dependence between the pre-exponential factor and the activation energy. ${ }^{21,22}$ The Meyer-Neldel establishes that there is a relation between the pre-exponential factor and the activation energy as follows:

$$
\sigma_{T}=\sigma_{T T} \cdot \exp \left(\frac{-E_{T}}{K T_{M N}}\right)
$$


$T_{M N}$ is called Meyer-Neldel temperature and $K T_{M N}$ the Meyer-Neldel energy, assuming that $v_{t h}$ and $N_{C}$ remains constant with the variation of the activation energy. We have obtained a value for the MN energy of 14 meV for the sample with a dose of $10^{13} \mathrm{~cm}^{-2}$ and a value of $9 \mathrm{meV}$ for the sample with a dose of $10^{14} \mathrm{~cm}^{-2}$.

This rule has been observed in various different systems. For example, we observed this behavior in silicon supersaturated with titanium instead of vanadium, ${ }^{19,23}$ and even we have observed it in silicon contaminated with iron (Fe) impurities. ${ }^{24}$ Figure 5 shows the capture cross section as a function of the activation energy for Si implanted with vanadium, with titanium and for silicon contaminated with iron. The MN rule has been found for other electrical properties as the conductivity or for diffusion measurements. For instance, it has been reported for the conductance of a bilayer obtaining supersaturating a Si wafer with some metals as vanadium, zirconium, titanium or chromium, ${ }^{25}$ and a value for the MN energy of $22 \mathrm{meV}$ was found. Coutts and Pearsall found a $\mathrm{MN}$ energy of $31 \mathrm{meV}$ for the reverse current of solar cells. ${ }^{26}$ As the MN rule appears in many situations, it has not associated to a particular process. It is known the MN rule takes place in disordered systems, and the processes that are affected by this rule involve multiple excitations (multi excitation entropy theory) ${ }^{27,28}$ as the process of emission or capture of a carrier in a deep level studied in this work. ${ }^{29}$

\section{CONCLUSIONS}

A study of deep levels energy distribution on silicon substrates supersaturated with vanadium has been carried out. ToF-SIMS profiles revealed concentrations below Mott limit for the measured implantation doses of $10^{13} \mathrm{~cm}^{-2}$ and $10^{14} \mathrm{~cm}^{-2}$. Using the thermal admittance spectroscopy technique, the energy levels of the vanadium implanted was measured. The energy value is around $E_{C}-250 \mathrm{meV}$ for $10^{13} \mathrm{~cm}^{-2}$ dose and $E_{C}-200$ for $10^{14} \mathrm{~cm}^{-2}$ dose. The energy position was almost constant for different reverse bias voltages, in a different way it happened in silicon doped with titanium that was previously studied. Moreover, the spectral photoconductivity, that was previously measured, started to increase when the photons energy was about $0.4 \mathrm{eV}$. Probably, the deep level that we are detecting is not responsible for the IB formation.

We have also detected that the capture cross section of the deep levels measured by TAS, follows the Meyer-Neldel rule, a process that usually appears on processes which involves multiple excitations, as happens in capture and emission processes. We have obtained a value for the $\mathrm{MN}$ energy of $15 \mathrm{meV}$ for $10^{13} \mathrm{~cm}^{-2} \mathrm{dose}$ 
and a value of $9 \mathrm{meV}$ for $10^{14} \mathrm{~cm}^{-2}$ dose. These values agrees with the previously obtained results for silicon supersaturated with titanium and for silicon contaminated with iron.

\section{ACKNOWLEDGMENTS}

Authors would like to acknowledge the CAI de Técnicas Físicas of the Universidad Complutense de Madrid for the ion implantation process and metallic evaporations. This work been supported by the Spanish MINECO TEC 2014 under grant 52512-C3-3-R, by the Project MADRID-PV (Grant No. 2013/MAE-2780) funded by the Comunidad de Madrid, by the Spanish MINECO TEC2013 under grant 41730-R, and by the Universidad Complutense de Madrid (Programa de Financiación de Grupos de Investigación UCM-Banco Santander) under grant 910173-2014D.

\section{References}

[1] A. Luque, and A. Martí, Phys. Rev. Lett. 78, 5014 (1997).

[2] W. Shockley, and H. J. Queisser, J. Appl. Phys. 32, 510 (1961).

[3] E. López, A. Datas, I. Ramiro, P. G. Linares, E. Antolín, I. Artacho, A. Martí, A. Luque, Y. Shoji, T. Sogabe, A. Ogura, and Y. Okada, Sol. Energy Matter. Sol. Cells 149, 15 (2016).

[4] J. P. Mailoa, A. J. Akey, C. B. Simmons, D. Hutchinson, J. Mathews, J. T. Sullivan, D. Recht, M. T. Winkler, J. S. Williams, J. M. Warrender, P. D. Persans, M. J. Aziz, and T. Buonassisi, Nat. Commun. 5, $3011(2014)$.

[5] E. García-Hemme, R. García-Hernansanz, J.Olea, D. Pastor, A. del Prado, I. Mártil, and G. GonzálezDíaz, Appl. Phys. Lett. 104, 211105 (2014).

[6] H. Boustanji, S. Jaziri, and J-L. Lazari, Sol. Energy Matter. Sol. Cells 159, 633 (2017).

[7] N. Tang, Q. Hu, A. Ren, W. Li, C. Liu, J. Zhang, L. Wu, B. Li, G. Zeng, S. Hu, Sol. Energy 157, 707 (2017).

[8] D. Recht, M. J. Smith, S. Charnvanichborikarn, J. T. Sullivan, M. T. Winkler, J. Mathews, J. M. Warrender, T. Buonassisi, J. S. Williams, S. Gradečak, and M. J. Aziz, J. Appl. Phys. 114, 124903 (2013).

[9] A. Luque, A. Martí, E. Antolín, and C. Tablero, Phys. B 382, 320 (2008). 
[10] H. Castán, E. Pérez, H. García, S. Dueñas, L. Bailón, J. Olea, D. Pastor, E. García-Hemme, M. Irigoyen, and G. González-Díaz, J. Appl. Phys. 113, 024104 (2013).

[11] J. Olea, M. Toledano-Luque, D. Pastor, E. San Andrés, I. Mártil, and G. González-Díaz, J. Appl. Phys. 107, 103524 (2010).

[12] J-W. Chen, A. G. Milnes, and A. Rohatgi, Solid-State Electron. 22, 801 (1979).

[13] J. Olea, M. Toledano-Luque, D. Pastor, G. González-Díaz, and I. Mártil, J. Appl. Phys. 104, 016105 (2008).

[14] J. Barbolla, S. Dueñas, and L. Bailón, Solid-State Electron. 35, 285 (1992).

[15] D. K. Schroeder, Semiconductor Material and Device Characterization, 2nd edn. (John Wiley \& Sons, New York, 1998).

[16] D. Pastor, J. Olea, A. del Prado, E. García-Hemme, R. García-Hernansanz, and G. González-Díaz, Sol. Energy Matter. Sol. Cells 104, 159 (2012).

[17] C. W. White, S. R. Wilson, B. R. Appleton, and F. W. Young, J. Appl. Phys. 51, 738 (1980).

[18] T. Sadoh, H. Nakashima, and T. Surushima, J. Appl. Phys. 72, 520 (1992).

[19] E. Pérez, S. Dueñas, H. Castán, H. García, L. Bailón, D. Montero, R. García-Hernansanz, E. GarcíaHemme, J. Olea, and G. González-Díaz, J. Appl. Phys. 118, 245704 (2015).

[20] E. García-Hemme, G. García, P. Palacios, D. Montero, R. García-Hernansanz, G. González-Díaz, and P. Wanhon, J. Phys. D: Appl. Phys. Accepted for publication.

[21] W. Meyer and H. Neldel, Z. Tech. Phys. 18, 518 (1937).

[22] Y. F. Chen, and S. F. Huang, Phys. Rev. B 44, 13775 (1991).

[23] E. Pérea, H. Castán, H. García, S. Dueñas, L. Bailón, D. Montero, R. García-Hernansanz, E. GarcíaHemme, J. Olea, and G. González-Díaz, Appl. Phys. Lett. 106, 022105 (2015).

[24] E. Pérez, H. García, H. Castán, and S. Dueñas, Semicond. Sci. Technol. 30, 035011 (2015).

[25] E. García-Hemme, R. García-Hernansanz, J. Olea, D. Pastor, A. del Prado, I. Mártil, and G. GonzálezDíaz, J. Phys. D: Appl. Phys. 48, 075102 (2015).

[26] T. Coutts, and N. Pearsall, Appl. Phys. Lett. 44, 134 (1984).

[27] A. Yelon, B. Movoghar, and R. S. Crandall, Rep. Prog. Phys. 69, 1145 (2006).

[28] A. Yelon, B. Movoghar, and H. M. Branz, Phys. Rev. B 46, 12244 (1992).

[29] D. V. Lang, and C. H. Henry, Phys. Rev. Lett. 35, 1525 (1975). 


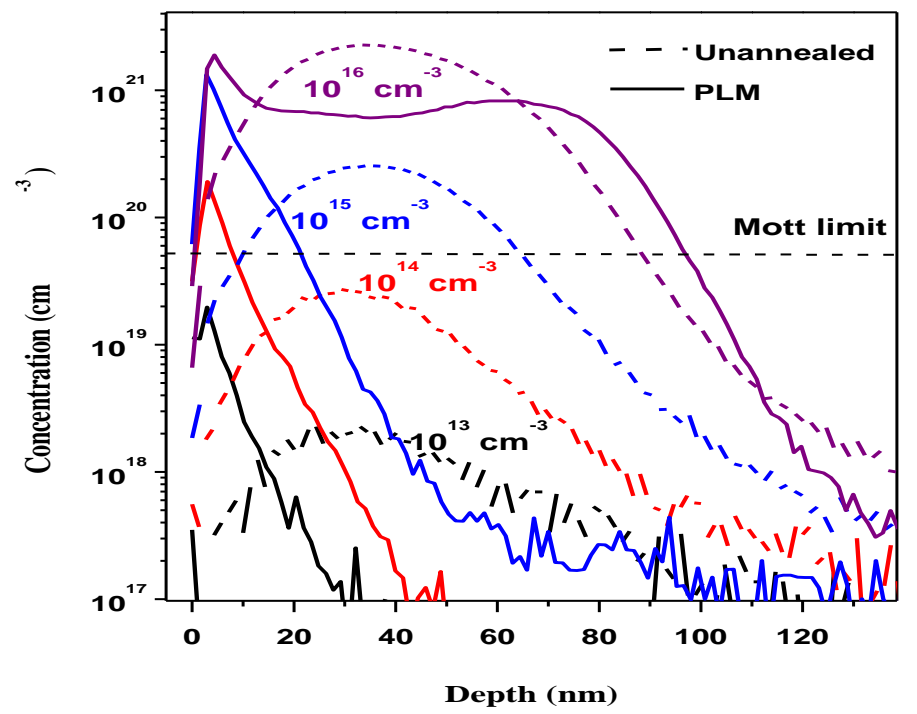

Figure 1. ToF-SIMS profiles of vanadium implanted samples with $10^{13}, 10^{14}, 10^{15}$ and $10^{16} \mathrm{~cm}^{-2}$ doses. Nonannealed (dashed lines) and PLM annealed (solid lines). 

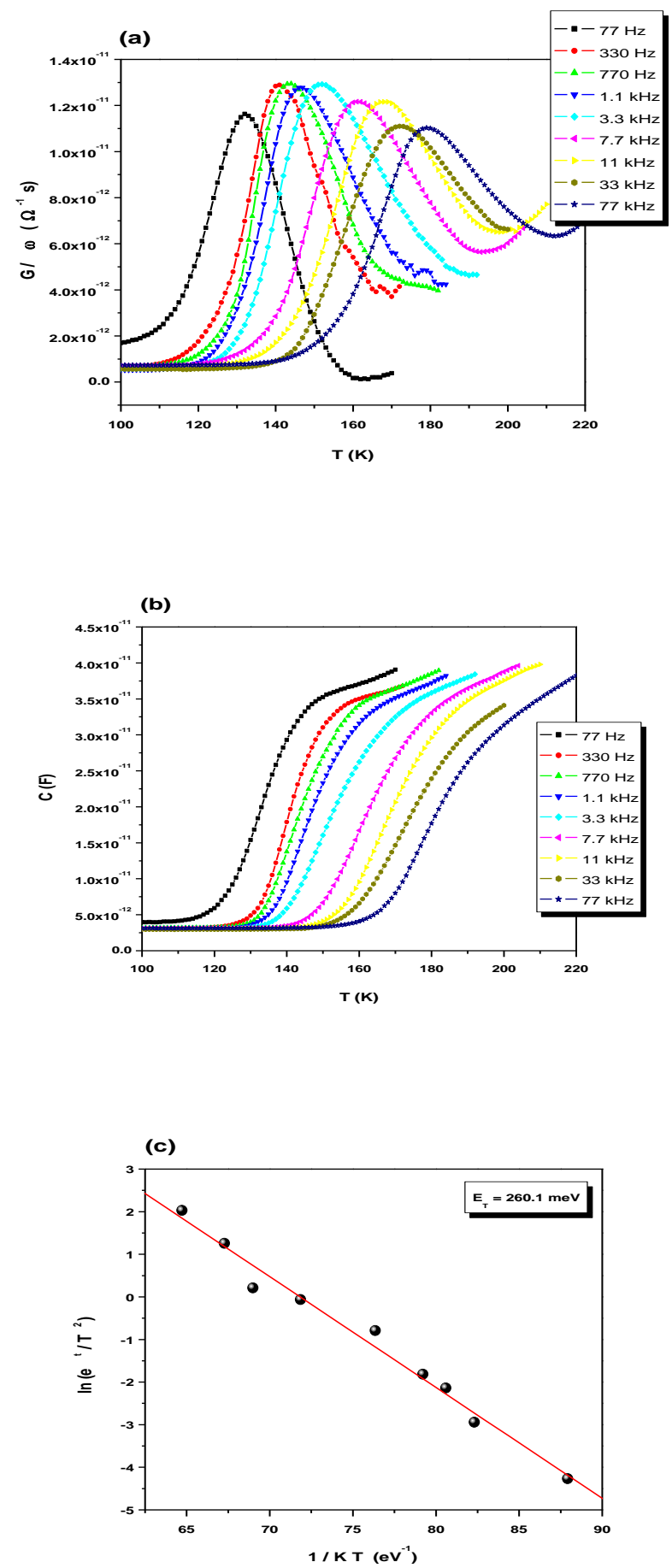

Figure 2. Thermal admittance spectroscopy corresponding to $10^{13} \mathrm{~cm}^{-2}$ implantation dose. No bias was applied to the sample. Conductance signal (a), capacitance signal (b) and Arrhenius plot (c). 


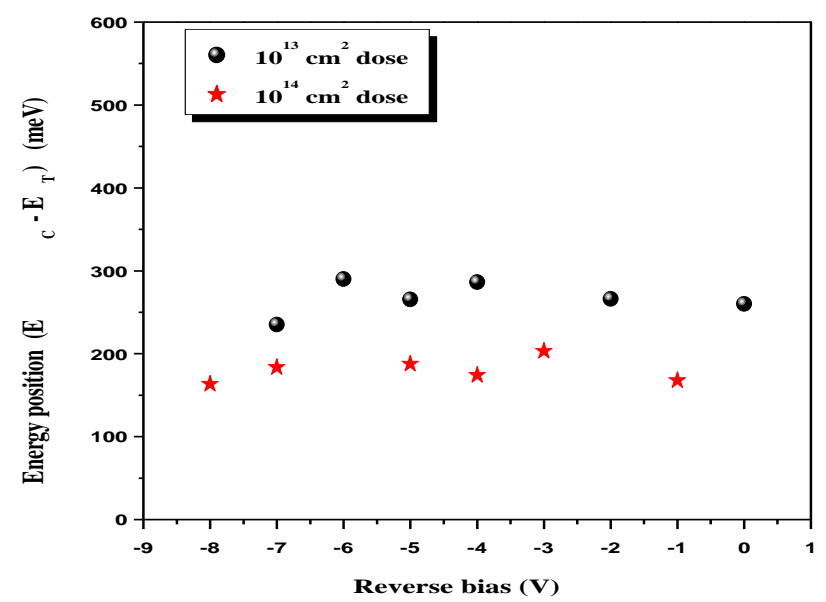

Figure 3. Vanadium energy position in the silicon band gap for several reverse bias applied and for the two applied doses. 


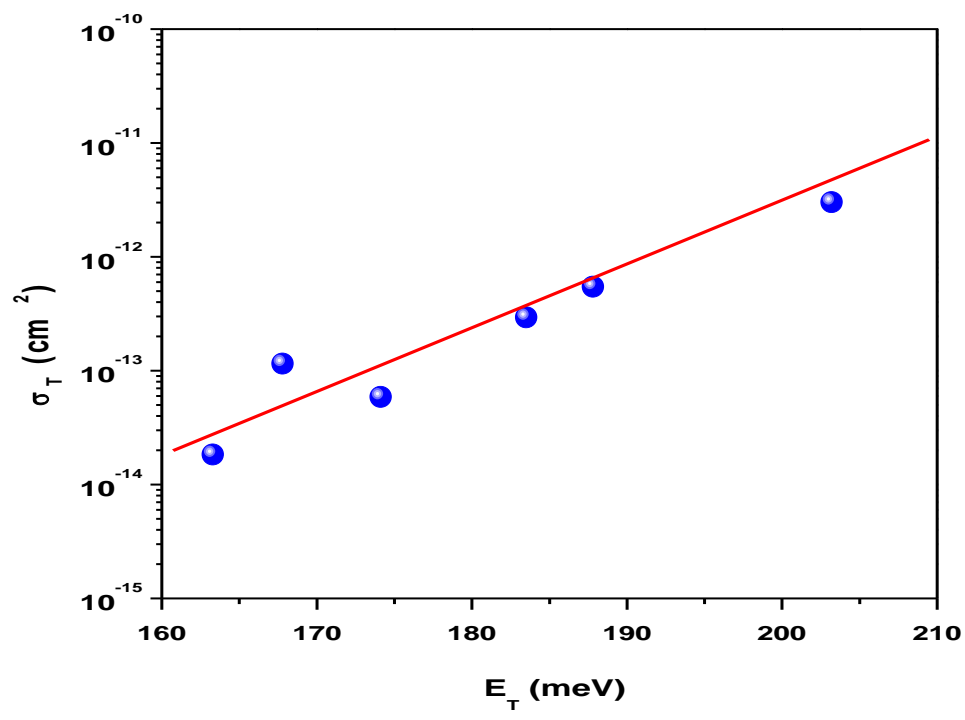

Figure 4. Capture cross section vs activation energy for sample implanted with $10^{14} \mathrm{~cm}^{-3}$ for all the bias measured. 


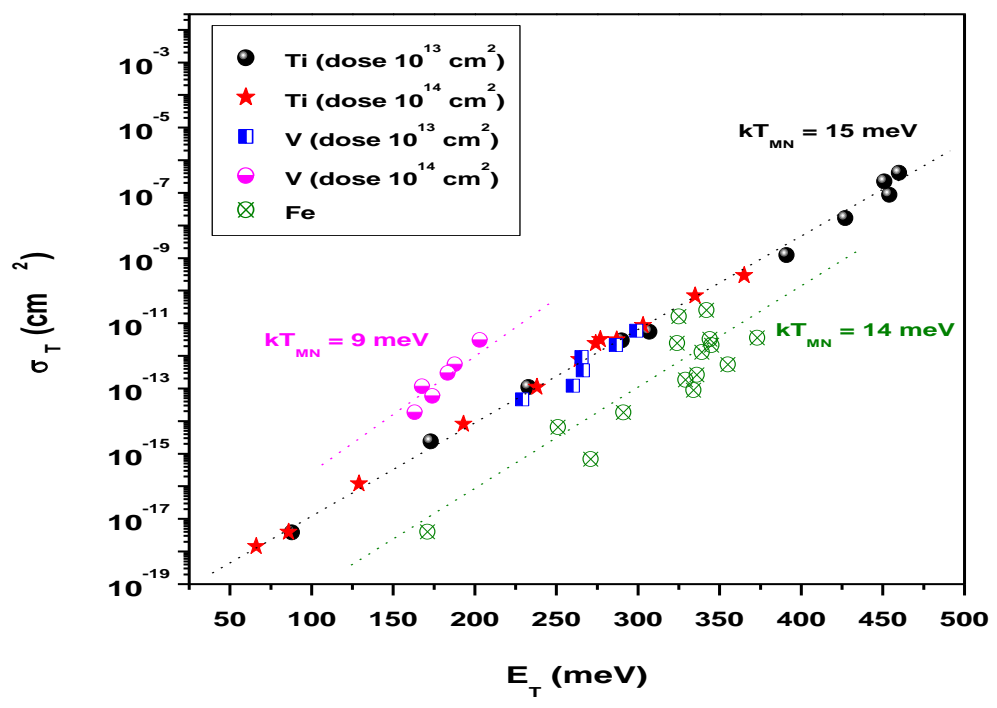

Figure 5. Capture cross section vs activation energy for samples implanted with $\mathrm{Ti}$, with $\mathrm{V}$ and contaminated with Fe. 